\title{
Executive functioning and prospective memory in young children
}

\author{
Caitlin E.V. Mahy*, Louis J. Moses \\ University of Oregon, United States
}

\section{A R T I C L E I N F O}

\section{Keywords:}

Prospective memory

Executive function

Retrospective memory

Preschool children

\begin{abstract}
A B S T R A C T
The current study examined the role of executive functioning (EF) in children's prospective memory (PM) by assessing the effect of delay and number of intentions to-be-remembered on PM, as well as relations between PM and EF. Ninety-six 4-, 5-, and 6-year-olds completed a PM task and two executive function tasks. The PM task required children to interrupt an ongoing card game to perform one action (single intention) or two actions (dual intention) with target cards after a short delay (1 $\mathrm{min}$ ) or a long delay ( $5 \mathrm{~min}$ ). There was no main effect of number of intentions or delay on the PM task. However, performance improved with age, and age and delay interacted such that 4-year-olds' performance remained the same after a long delay whereas 5-year-olds' performance improved after a long delay. We suggest that the age by delay interaction is a product of age differences in cognitive monitoring. Working memory but not inhibitory control predicted PM with age controlled. We argue that an executive function framework permits an integrative understanding of many processes involved in young children's prospective memory.
\end{abstract}

(c) 2011 Elsevier Inc. All rights reserved.

Young children often need to remember to carry out an action at some point in the future, whether it is more or less immediately, as in putting the juice back into the refrigerator after pouring a drink, or at some later point in time, as in bringing a jacket to school. Actions such as these depend on successful prospective memory (PM), the ability to remember to perform intended activities (Kliegel \& Jäger, 2007). Einstein and McDaniel (1990) described two distinct types of prospective memory: time-based prospective memory, where one must remember to perform an action at a certain point in

\footnotetext{
* Corresponding author.

E-mail address: cmahy@uoregon.edu (C.E.V. Mahy).
} 
time or after a certain amount of time has elapsed, and event-based prospective memory, where one must remember to perform an action when a specific event occurs.

The development of PM follows an inverted U-shape function from childhood to old age, with young and middle aged adults having peak PM (Kliegel, Mackinlay, \& Jäger, 2008; Zimmermann \& Meier, 2006). Much attention has been paid to this ability in older adults because declining PM compromises the ability to function independently (Einstein \& McDaniel, 1990). The literature on PM during childhood is small compared to the literature on PM in older adults and also to the vast literature on children's retrospective memory (RM) (e.g., Farrar \& Goodman, 1992; Peterson, 2002). Moreover, most developmental studies of PM have focused on school-aged children (e.g., Ceci \& Bronfenbrenner, 1985; Kerns, 2000; Mackinlay, Kliegel, \& Mäntylä, 2009; Martin \& Kliegel, 2003). What research there is in early childhood has focused on event-based PM because of limited time reading abilities in children of this age.

Forgetfulness in young children might not be viewed as a serious problem because of the scaffolding presence of caregivers. However, once children enter preschool, they are increasingly asked to remember to do things. Parents, teachers, and memory aids such as reminder letters facilitate this remembering, but increasingly the burden of prospective remembering shifts to children as they develop, with important implications for academic functioning and interpersonal relations (McCauley \& Levin, 2004).

\section{An executive function framework for PM}

Domain-general cognitive abilities likely have an impact on children's PM. One such ability, executive functioning $(\mathrm{EF})$, has been argued to play a particularly important role in the development of PM (Atance \& Jackson, 2009; Kvavilashvili, Messer, \& Ebdon, 2001; Mackinlay et al., 2009; Rendell, Vella, Kliegel, \& Terrett, 2009; Wang, Kliegel, Liu, \& Yang, 2008; Ward, Shum, McKinlay, Baker-Tweney, \& Wallace, 2005; West, 1996). EF, the conscious control of thought and action, develops rapidly in early childhood (Zelazo, Carlson, \& Kesek, 2008), and various components of EF including planning, monitoring, working memory, and inhibitory control have all been suggested as important for successful PM (Marsh \& Hicks, 1998; West \& Craik, 1999). PM has both a retrospective and prospective component (Brandimonte, 1991). For example, remembering the content of the intention relies on retrospective memory whereas remembering to perform the action at the appropriate time relies on a prospective component. Executive processes may be especially involved in the prospective component of PM (Burgess, 2000).

Two influential models of PM that implicate EF are the preparatory attentional and memory processes (PAM) model and the multiprocess model. In the PAM model, controlled processes that are working prior to the presentation of cues to the prospective action are necessary components of successful event-based prospective memory (Smith, 2003; Smith \& Bayen, 2004). These controlled processes, referred to as preparatory attentional processes in the PAM model, carry out effortful monitoring of the environment for the appearance of the prospective cue. In the multiprocess model it is argued that PM does not necessarily require effortful strategic processes but that specific PM task attributes determine whether such processes are likely to be engaged (Guynn, McDaniel, \& Einstein, 2001; McDaniel, Robinson-Riegler, \& Einstein, 1998). For example, McDaniel and Einstein (2000) have suggested that strategic, effortful processes are more likely to occur under conditions where there is: higher perceived task importance, a weaker association between the triggering cue and the action, and a more engaging, attention-demanding ongoing task. These two theories differ in the suggested role of automatic processes but are similar in recognizing the role of controlled processes at least under certain conditions. If such capacity-consuming processes are potentially important in PM as both theories suggest, individual differences in EF may play a role in PM especially during early childhood when the abilities needed to consciously control thoughts and actions are still developing (Zelazo et al., 2008).

A typical event-based PM task involves a prospective action (e.g., placing a card of a certain type in a box) that must be completed in the future after a specific event occurs. This prospective action typically interrupts an ongoing task (e.g., card sorting) that must be paused and then resumed after the prospective intention has been carried out (Kvavilashvili et al., 2001). Four features of event-based PM tasks that might pose difficulty for children are: (1) the nature of the prospective intention, (2) the 
length of the delay before carrying out the intention, (3) the nature of the ongoing task in which the prospective action is embedded, and (4) the nature of the cue that signals the need to carry out the prospective intention (see also Ellis \& Kvavilashvili, 2000; Brandimonte \& Passolunghi, 1994).

How might EF be involved in these various aspects of event-based PM tasks? First, some intentions are more memorable than others in that they are high in perceived importance or personal relevance (e.g., intending to go to a friend's birthday party after school versus intending to do chores). Such intentions presumably require less inhibitory control in that they should be less susceptible to interference from other stimuli. Further, the number of prospective intentions to be remembered should also influence PM through its impact on working memory. Hicks, Marsh, and Cook (2005) suggest that prospective intentions may fade in and out of conscious working memory similar to the way that material waxes and wanes out of focal attention in Cowan's (1995) theory of working memory and attention. As a result, having to remember two or more intentions may place greater demands on working memory than having to remember one.

Second, intentions that must be retained over longer delays should place heavier demands on the retrospective component of PM. At the same time, however, executive processes may be implicated in that longer delays may provide greater opportunities for active strategizing about the need to remember the intention. Consequently, the impact of delay on PM may not be straightforward.

Third, the nature of the ongoing task (e.g., how engaging or difficult the task is) should also affect PM through its impact on inhibitory control. That is, children need to inhibit the ongoing activity in order to carry out the prospective intention (Kvavilashvili et al., 2001; Wang et al., 2008), and doing so will likely be more difficult if cognitive resources are consumed in an engrossing or challenging task. Further, children with better working memory may have more resources available for juggling the competing demands of the ongoing and prospective tasks, and may be better at selecting relevant versus irrelevant information to maintain in working memory (Awh \& Vogel, 2008; Hicks et al., 2005; Vogel, McCollough, \& Machizawa, 2005).

Fourth, the salience and explicitness of the cue to carry out the prospective intention should impact inhibitory control in that a strong cue should make it easier to inhibit the current task in order to shift to the PM task. In these various ways, EF may thus provide a framework for understanding many of the developmental processes underlying successful PM.

\section{Evidence for the role of EF in PM}

\subsection{Nature of the intention}

With respect to forming and retaining the content of an intention, the interest of the to-beremembered activity (Somerville, Wellman, \& Cultice, 1983) has an impact on young children's PM, with high interest intentions (e.g., getting ice cream) being performed more often than low interest intentions (e.g., turning off the sprinkler). In addition, in adults a manipulation requiring the content of dual intentions to be retained, thereby increasing working memory storage load, and potentially impacting the need for strategic resources, resulted in reduced ongoing task performance, although it did not decrease performance on the PM task itself (Hicks et al., 2005). Further, age differences between younger and older adults are more likely to emerge when there are several different prospective targets or complex intentions (Einstein, Holland, McDaniel, \& Guynn, 1992; Kliegel, McDaniel, \& Einstein, 2000). However, no study has assessed children's ability to remember more than one prospective intention. Thus, an interesting issue is whether doing so causes a decrement in young children's PM (or on ongoing task performance).

\subsection{Length of delay}

The impact of delay between the time at which the intention is formed and the time at which it must be carried out has not been thoroughly examined in children. One might expect that PM would decrease with a longer retention interval, as is classically the case with retrospective memory (e.g., Powell \& Thomson, 1996; Peterson, 2002). Interestingly, however, Hicks, Marsh, and Russell (2000) found that adults' PM improved with an increase in the retention interval between the prospective 
instruction and the prospective action from 2.5 to $15 \mathrm{~min}$. They suggested that a longer retention interval allowed for more opportunities to recall the prospective intention.

Only two studies have investigated the effect of the retention interval on children's event-based PM. In a naturalistic study, Somerville et al. (1983) found that 2- to 4-year-old children were better at reminding their mothers to do something after a short delay (5-10 min) than after a very long delay (the following afternoon or next morning). In contrast, Nigro, Senese, Natullo, and Sergi (2002) found that 7 - to 11 -year-olds' PM suffered with delay (15 min compared to $10 \mathrm{~min}$ ) when the prospective task was time-based but not when it was event-based. These studies differ greatly in both age of participants and length of delays. PM may decline over very long periods possibly because of difficulties in retrieving the intention from long term memory. However, it may be less affected, or even enhanced, over intermediate delays because there is less reliance on long term memory and also sufficient opportunity to bring to mind and monitor the prospective intention. In addition, there may be a developmental progression such that delay has a detrimental effect on younger children but less of an impact on older children as they become more sophisticated users of memory strategies and their EF continues to develop. The effect of retention interval on children's PM therefore deserves further investigation.

\subsection{Nature of ongoing task}

Ongoing task performance has often been used as a measure of overall engagement in the PM task, but also to detect trade-offs such as reduced task performance as a consequence of sustained PM performance (or vice versa). Several researchers have manipulated the nature of the ongoing task during a PM task. Wang et al. (2008) varied working memory load during the ongoing task by asking children (aged three to five years) either to memorize or not memorize cards as they named them. The heavier working memory load in the ongoing task negatively affected PM response time, although not accuracy. In addition, young children's PM has been shown to be worse when the ongoing task must be interrupted in order to complete a prospective action compared to when the task is first completed and then immediately followed by the PM cue (Kvavilashvili et al., 2001; Wang et al., 2008). Wang et al. attributed the negative effects of task interruption on PM performance to deficits in children's inhibitory abilities. They suggested that it is difficult for children to suppress a prepotent response in an ongoing task in order to carry out a novel, prospective action. In contrast, when a task is completed before the action needs to be carried out, the inhibitory component is removed. There was, however, no independent measurement of inhibitory control in Wang et al.'s or Kvavilashvili et al.'s studies. Finding a relation to individual difference measures of inhibitory control would strengthen the inhibitory interpretation of performance in the task interruption condition.

\subsection{Nature of prospective cue}

The recognition of a prospective cue presents a challenge because the response must be selfinitiated. Children themselves need to notice the cue and recognize its significance. The salience of relevant physical cues (Meacham \& Colombo, 1980) has an impact on 6- to 8-year-old children's PM (e.g., the presence of a toy clown made children more successful in reminding an experimenter to open a toy box after a 7 min interval compared to when no clown was present). However, there is evidence that younger children (3- to 5-year-olds) may have difficulty using external cues to improve their PM (e.g., a picture of the target placed in front of a computer screen did not aid children's performance; Guajardo \& Best, 2000). External cues, like prospective intentions, may also be affected by intrinsic interest but this has not been explicitly studied in children.

\subsection{The current study}

The current study was designed to address two aspects of the EF framework, as well as some outstanding issues in the developmental PM literature. Specifically, we examined the effect of the retention interval and the number of to-be-remembered prospective intentions on 4- to 6-year-old children's PM. We chose this age range because executive functions are rapidly developing during this period of childhood (Carlson, 2005; Diamond, 1988; Zelazo et al., 2008). Further, there are associated 
changes in metacognition during this period; for example, in reflective awareness (Zelazo \& Frye, 1998; Zelazo, 2004), theory of mind (Wellman \& Liu, 2004), and meta-memory (Joyner \& Kurtz-Costes, 1997). These changes may further contribute to age-related differences in prospective memory.

We chose a relatively short delay contrast ( $1 \mathrm{~min}$ vs. $5 \mathrm{~min}$ ) because of the young age group. As noted earlier, young children's PM has been found to decline over very long delays (Somerville et al., 1983) but it is unclear whether their PM declines or improves over shorter delays. To further assess the involvement of executive processes, we also contrasted the need to remember one intention with the need to remember two intentions. Finally, we explored whether independent measures of inhibitory control and working memory are related to PM. Adult individuals with a smaller working memory capacity experienced more task interference which led to poorer cue detection in an event-based PM task (Smith, 2003). To our knowledge, however, no prior studies have examined whether performance on EF tasks relates to PM in young children, although such a relation has been reported in 6- to 12year-olds with time-based PM tasks (Kerns, 2000; Mackinlay et al., 2009). We chose widely used EF measures on which children's performance improves markedly in the age range under study (Carlson, 2005). We focused on inhibitory control and working memory as these aspects of executive function have been specifically implicated in PM (Kerns, 2000; Mackinlay et al., 2009; Wang et al., 2008). The day/night task (Gerstadt, Hong, \& Diamond, 1994) was used as a measure of conflict inhibitory control. As in PM tasks, children in the day/night task need to remember information (such as the task rules) while inhibiting a dominant response. This task is positively correlated with other measures of conflict inhibition (Carlson \& Moses, 2001). Backward digit span (Davis \& Pratt, 1996) was used as a measure of working memory. This classic working memory measure requires children to both store information and to manipulate it in order to repeat digits in reverse order. Carlson (2005) found that backward digit span was a developmentally sensitive measure of working memory in 4- to 6-year-old children.

\section{Method}

\subsection{Participants}

Ninety-six children participated. Eleven additional children were excluded for failing control questions. The final sample included 324 -year-olds $(M=4.41, \mathrm{SD}=.45), 325$-year-olds $(M=5.46, \mathrm{SD}=.34)$, and 326 -year-olds $(M=6.47, \mathrm{SD}=.32)$ with equal numbers of girls and boys in each age group. Children were recruited from local preschools and from a university database. The majority of children were Caucasian and from middle-class backgrounds, reflecting the demographics of the population from which they were sampled.

\subsection{Procedure}

Children were tested in the lab or a quiet area of their preschool and their performance was videotaped. As is standard practice in individual differences research, tasks were given in a fixed order as follows: PM task, retrospective memory task (RM), digit span task, and day/night task.

\subsection{Measures}

\subsubsection{Prospective memory task}

The PM task consisted of a card-sorting game requiring children to name objects depicted in four stacks of cards and to provide a novel response to certain target cards (after Kvavilashvili et al., 2001). Children were assigned within age group to one of four conditions: short delay with a single intention, long delay with a single intention, short delay with dual intentions, or long delay with dual intentions. Assignment was random with the constraints that an equal number of girls and boys were in each condition and that mean age was approximately equal across conditions. There were no significant differences in age across conditions within age groups (all $p s>.55$ ). The delay between the introduction of the PM task rules and the card sorting was either $1 \mathrm{~min}$ (short) or $5 \mathrm{~min}$ (long). In single intention conditions, one type of target card (animals) served as a cue to perform a particular action, whereas 
in dual intention conditions two different types of target cards (animals and cars) cued two distinct actions.

Children were first introduced to Morris the Mole, a stuffed animal, who had poor daytime vision. They were asked to help Morris learn what was on the cards by naming the pictured objects. Cards were $3 \times 3$ in. color pictures of everyday objects (e.g., food, furniture, and toys). Target cards pictured animals or cars. Children were told that Morris would also love it if they would draw pictures for him. In addition, they were told that Morris was afraid of animals and that if they saw an animal card, they should hide it from Morris by placing it in a box approximately four feet behind them. Children in the dual intention conditions were also told that Morris loves cars. They were told that when they saw a card depicting a car, they should place it in a box beside Morris so that he could see it. As practice, children were asked to name the first two cards and to place them face down on the table in front of Morris.

Children next drew pictures for either 1 or 5 min depending on delay condition. They were then asked to name the first stack of cards. Subsequently, children alternated between drawing a picture for 1 min and naming a stack of cards until they had named all four stacks of cards. Each stack contained 13 cards: Of these, two were target cards (two animals in the single intention condition, and an animal and a car in the dual intention condition). Target cards were placed in a fixed position in each stack, the 7th and 12th cards in the first stack, the 4th and 10th cards in the second stack, the 6th and 11th cards in the third stack, and the 5th and 10th in the fourth stack. In the dual intention condition, in the first two stacks the animal card appeared before the car card, whereas in the last two stacks, the car card appeared prior to the animal card.

After children finished naming the four stacks they were asked "what were you supposed to do when you saw an animal (or an animal and a car)?" This control question checked that they had remembered the initial rules and thus that their forgetting did not arise from a RM failure surrounding the instructions. Eleven children were excluded from final analysis for failing this control question: six 4-year-olds, three 5-year-olds, and two 6-year-olds. Children were given a score out of eight based on the number of target cards they placed in the appropriate box.

\subsubsection{Retrospective memory}

To measure children's RM, they were given a recognition test of cards presented in the four stacks. This measure assessed how well children had processed the distracter cards and was given to examine the possibility that children might perform well in some conditions on the PM task at the cost of memory for the ongoing task. Children were shown 22 non-target cards, half of which had been seen previously, and were asked if they had seen the cards in the game with Morris the Mole. Novel cards were from the same general categories as previously seen cards. Children were scored on their recognition accuracy out of 22 .

\subsubsection{Digit span task}

To measure working memory, children completed the digits forward and digits backward subscales from the WISC-III (Wechsler, 1991). We used the backward digit span task as the measure of working memory but gave the forward digit span as a warm-up, in order to familiarize children with the task. In the digits forward subscale, they were asked to repeat a series of numbers after the experimenter read them aloud. They began with two numbers and after completing two trials successfully, an additional number was added. The task ended when they failed two consecutive trials. The digits backward task was identical to the digits forward task except children had to repeat the digits backward. The same criterion was used for terminating the task. Performance was scored based on how many backward digit strings children were able to repeat correctly.

\subsubsection{Day/night task}

To measure inhibitory control, children completed the day/night task (Gerstadt et al., 1994). This task required children to say "day" when they saw a card depicting the moon and stars, and "night" when they saw a card depicting the sun. Children were shown both cards and the experimenter demonstrated how to name them. They were then given two practice trials, one day and one night. If they responded correctly on both trials, these were counted as the first two test trials. If they 
Table 1

Means and standard deviations for all measures.

\begin{tabular}{|c|c|c|c|c|c|c|}
\hline \multirow[t]{3}{*}{ Measure } & \multicolumn{6}{|l|}{ Age } \\
\hline & \multicolumn{2}{|c|}{ 4-year-olds } & \multicolumn{2}{|c|}{ 5-year-olds } & \multicolumn{2}{|c|}{ 6-year-olds } \\
\hline & $M$ & SD & $M$ & SD & $M$ & SD \\
\hline Prospective memory & 3.97 & 3.49 & 6.88 & 2.32 & 7.16 & 1.53 \\
\hline Retrospective memory & 18.05 & 4.97 & 19.43 & 3.64 & 20.91 & 0.99 \\
\hline Backward digit span & 0.58 & 1.07 & 1.96 & 1.53 & 2.91 & 1.08 \\
\hline Day/night (accuracy) & 13.53 & 2.53 & 13.50 & 2.73 & 13.83 & 3.08 \\
\hline
\end{tabular}

Note: Possible range of scores for each task: Prospective memory (0-8); Retrospective memory (0-22); Backward digit span (0-6); day/night accuracy (0-16). Higher scores represent better performance.

responded incorrectly, the rules and practice trials were repeated. No children needed to repeat these trials more than once. Sixteen test cards were then presented in a fixed, pseudorandom order (n,d,d,n,d,n,n,d,d,n,d,n,n,d,n,d). Children were given an accuracy score out of 16 based on the first response they made to each card.

\section{Results}

Table 1 shows the means and standard deviations of performance on all tasks for each age group. No effect of gender was found in preliminary analyses for any of the variables.

\subsection{Prospective memory task}

Table 2 shows means and standard deviations in each PM condition in the three age groups. A 3 (age) $\times 2$ (delay) $\times 2$ (intention) between group ANOVA was conducted on the number of correct actions children remembered to carry out in response to target cards. Performance improved with age, $F(2,84)=14.97, p<.001, \eta^{2}=.26$, but there were no significant main effects of intention or length of delay. There was, however, a significant interaction between delay and age, $F(2,84)=3.10, p=.05$, $\eta^{2}=.07$. Fig. 1 illustrates the interaction. Tests of simple effects revealed that four and five year olds did not differ in performance in the short delay condition, but 5-year-olds out performed 4-year-olds in the long delay condition, $F(1,84)=24.27, p<.001$. There was a trend toward 4-year-olds performing worse in the long delay compared to the short delay condition, $F(1,84)=2.50, p=.12$, whereas 5 -year-olds showed the opposite pattern, performing marginally better in the long delay than the short delay condition, $F(1,84)=3.68, p=.06$. Six-year-olds performed equally well and close to ceiling in both delay conditions. They performed significantly better than 4-year-olds (but not 5-year-olds) in both the short and long delay conditions, $F s(2,84)>6.8, p s<.01$.

Although there was no significant main effect of intention, children in the dual intention condition remembered to place the pictures of the car in the box $(M=3.22, \mathrm{SD}=1.53)$ more often than they remembered to hide the animals pictures in the box $(M=2.58, S D=1.60), t(47)=3.18, p<.01$, indicating that one of the intentions was carried out more successfully than the other.

Table 2

Means and standard deviations for the PM task broken down by age and condition.

\begin{tabular}{llllll}
\hline & \multicolumn{2}{l}{ Single intention } & & \multicolumn{2}{l}{ Dual intention } \\
\cline { 2 - 3 } & Short delay & Long delay & & Short delay & Long delay \\
\hline 4-year-olds & $4.50(3.78)$ & $4.13(3.68)$ & & $4.88(3.44)$ & $2.38(3.20)$ \\
5-year-olds & $5.75(3.58)$ & $7.88(.35)$ & & $6.25(2.61)$ & $7.63(.74)$ \\
6-year-olds & $7.75(.70)$ & $7.13(2.10)$ & $6.75(1.49)$ & $7.00(1.60)$ \\
\hline
\end{tabular}

Note: $n=8$ per cell. 


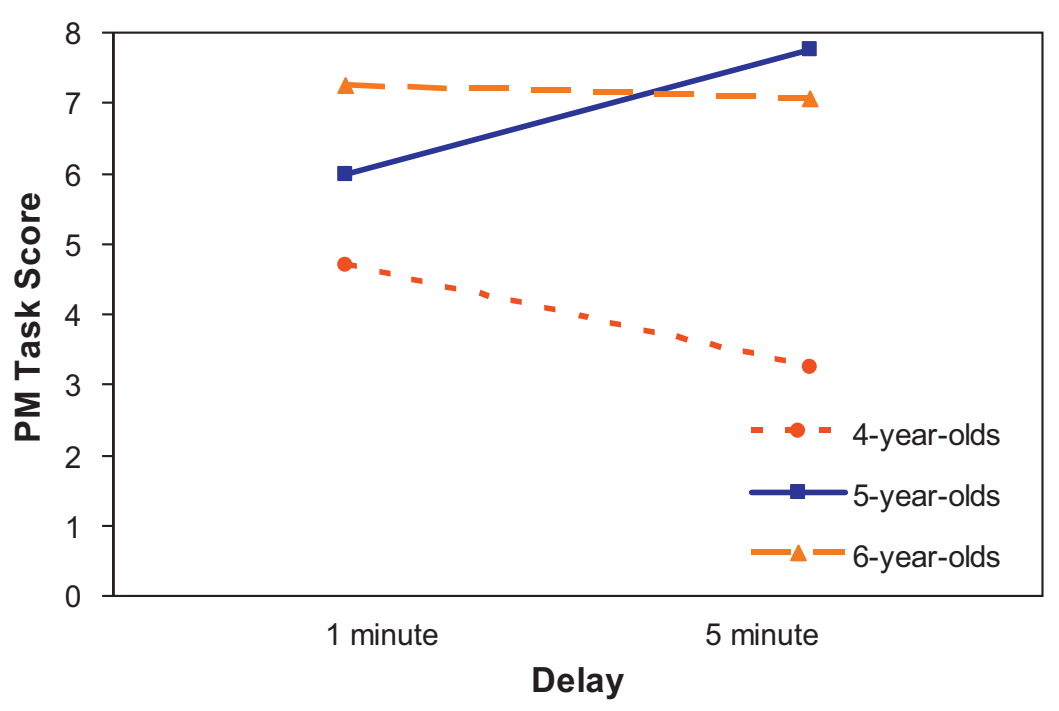

Fig. 1. Performance on the PM task (possible scores range from 0 to 8 ) by age and delay condition.

\subsection{Retrospective memory}

A 3(age) $\times 2$ (delay) $\times 2$ (intention) ANOVA was conducted on the number of cards children accurately recognized as old or new from the non-target cards presented during the PM task. RM for these cards did not differ depending on delay or intention condition. There was however an effect of age, with older children making more accurate judgments than younger children, $F(2,84)=3.49, p<.05$, $\eta^{2}=.08$ (see Table 1 ). A trend analysis revealed that the effect of age was linear, $F(1,84)=3.50, p<.05$. Nonetheless, children's RM was generally very good and well above chance at each age, $t s(31)>8.37$, ps $<.001$.

\subsection{Relation between PM and executive function}

Table 3 shows Bonferroni corrected $(p<.005)$ Pearson's correlations among all tasks. Age in months was significantly related to the digits backward task but not to performance on the day/night task. In addition, backward digit span was significantly correlated with performance on the PM task. Importantly, this correlation remained significant even with age controlled, $r(91)=.33, p<.01$. The day/night task showed a weak but non-significant correlation with performance on the PM task. Children's RM for the non-target cards was not related to the backward digit task, day/night task or to PM.

\subsection{Controlling for RM, working memory, and inhibitory control}

As a final analysis, we entered RM, working memory (backward digit span), and inhibitory control (day/night) into an 3 (age) $\times 2$ (delay) $\times 2$ (intention) ANCOVA to control for the possibility that individual differences in these abilities might account for the condition differences in PM performance. RM and inhibitory control did not significantly co-vary with PM performance, but working memory

Table 3

Correlations among prospective memory, retrospective memory, executive function, and age.

\begin{tabular}{|c|c|c|c|c|}
\hline & Age & PM & RM & BDS \\
\hline Prospective memory & $.44^{*}$ & & & \\
\hline Retrospective memory & .34 & .11 & & \\
\hline Backward digit span & $.52^{*}$ & $.48^{*}$ & .18 & \\
\hline Day/night & .16 & .17 & .01 & .01 \\
\hline
\end{tabular}

Note-PM: prospective memory (0-8); RM: retrospective memory (0-22); BDS: backward digit span (0-14); day/night (0-16); degrees of freedom range from 89 to 94 .

${ }^{*} p<.005$, Bonferroni corrected. 
did, $F(1,77)=11.20, p<.01$. Importantly, however, the main effect of age and the interaction between age and delay remained significant after controlling for working memory, RM, and inhibitory control, $\operatorname{Fs}(2,77)>3.45$, $p s<.05$. The obtained interaction is thus not simply due to age-related changes in RM, working memory, or inhibitory control.

The difference between 4-year-olds and 5-year-olds performance at a long delay remained highly significant after controlling for working memory, RM, and inhibition, $F(1,77)=26.62, p<.001$. Further tests of simple effects revealed that 5 -year-olds performance in the long delay was significantly better than in the short delay, $F(1,77)=4.33, p<.05$, whereas 4 -year-olds performance in the short and long delay did not differ, $F(1,77)=1.24, p=.26$. Differences in performance between 4 - and 6 -year-olds remained significant in the short delay and in the long delay conditions, $F s(1,77)>11.77, p s<.01$.

\section{Discussion}

Prospective memory is a critical ability for successful functioning in everyday life, but one that is surprisingly understudied in early childhood. In addition, although executive function has been proposed as important to PM, the relation has not been thoroughly examined empirically particularly in young children. In this study we suggested $\mathrm{EF}$ as a framework for understanding factors that affect PM and examined the effect of delay and number of intentions on PM in 4- to 6-year-old children. We also explored relations between working memory, inhibitory control, and PM, to further test the EF framework.

Delay between the time at which the prospective intention is formed and when it is carried out (the retention interval) and the number of intentions to be retained were two factors predicted to influence PM performance via working memory and inhibitory control. Although there was no main effect of delay, a significant interaction between age and delay emerged. Four-year-olds' PM was significantly worse than 5-year-olds' after a longer delay whereas after a short delay 4- and 5-year-olds' PM was not significantly different. As might be expected from RM findings (Peterson, 2002), 4-year-olds' performance tended to worsen after a long delay compared to a shorter delay, although this decline did not reach significance. In marked contrast, 5-year-olds showed significant improvement following a long delay after controlling for RM, working memory, and inhibitory control. This result is consistent with Hicks et al.'s (2000) similar findings with adults. Hicks et al. suggested that with a longer delay interval with breaks between activities, there are more opportunities to reflect on the intention, and it may be that 5-year-olds are taking advantage of such opportunities. In contrast, 4-year-olds may not capitalize on a longer delay to remind themselves of their goal or intended action. We speculate that the differential effect of delay on children of different ages may be a function of developmental changes in cognitive monitoring and introspection over the preschool years. Flavell, Green, and Flavell (2000) found that 5-year-olds may be beginning to use introspection and are developing an increased awareness of their thought processes. Children who are more aware of their thoughts may be more likely to think about their prospective intentions, particularly when given longer periods of time to do so.

Future research will need to examine the relation between PM and introspective and monitoring abilities. For example, if the monitoring account is correct, PM should deteriorate with a more difficult task during the delay period because it would presumably prevent or limit monitoring (see Marsh \& Hicks, 1998). Einstein and McDaniel (1996) suggest that participants are more likely to think of the prospective intention or rehearse it during easier tasks. In our study, the task that children completed during the delay period, drawing pictures, was engrossing and in addition may have been more difficult for 4-year-olds than for 5- and 6-year-olds. If so, 5-year-olds and 6-year-olds may have been better able to take advantage of the delay to the benefit of their PM. Research manipulating task difficulty during the delay will help to delineate what generates age differences in the effects of delay.

Surprisingly, the number of intentions to be remembered had no effect on PM (or on RM). The EF framework would predict that with a high enough working memory load, a decrease in PM would occur because working memory would consume cognitive resources normally used to monitor the environment for prospective cues. The dual intention condition should require additional cognitive resources and therefore lead to a decrease in PM or in performance on the ongoing task. However, children performed similarly when asked to remember two intentions compared with one intention. 
The lack of effect of intention in our study is inconsistent with findings from adults. In older adults, a greater number and more complex intentions lead to decreases in PM (Einstein et al., 1992; Kliegel et al., 2000). Further, Hicks et al. (2005) found that although having to remember dual intentions did not affect younger adults' PM, it did lead to decreased ongoing task performance. In contrast, children's RM for our ongoing task was generally very good and seemingly not affected by the extra working memory load in the dual intention condition.

There are several potential explanations for the lack of effect of remembering to carry out dual versus single intentions. One possibility is that we may have simply been unable to detect the effect in the current study. For example, with increased power, we may have found significant differences between 4-year-olds' performance in the long delay, dual intention condition compared to the three other conditions, as suggested by the direction of our results (see Table 2). In addition, with respect to the ongoing task, the RM task that we used may have been insensitive to our working memory manipulations as evidenced by the fact that although performance improved with age, all children performed quite well on the recognition of previously seen distracter cards. A more demanding RM task (e.g., recall) or a more direct measure of ongoing task performance, such as response latency during the ongoing task itself, may have revealed more subtle effects of working memory load.

Relatedly, our working memory manipulation may not have been strong enough. For example, the box for the cars in the dual intention condition was placed in front of children and so may have acted as a helpful visual cue for completing the action. In support of this explanation, children in the dual intention condition were significantly better at placing the car cards than the animal cards in the box. Alternatively, having to sort two distinct targets may have added interest to the task such that children overcame the increased working memory demand of the dual intention condition. Further, it is possible that because the intentions made reference to either Morris's likes or dislikes, the dual intentions may not have been represented as two distinct intentions (to hide the animals in one box and to place the cars in another box), but rather hierarchically embedded under a single intention (to please Morris).

Finally, it might be argued that carrying out the additional intention did not require working memory at all but rather retrospective memory for the content of the intention. Some prospective memory theories assume that individuals do not typically maintain prospective intentions in mind, but rather that these intentions are automatically retrieved when the appropriate target appears (Brandimonte, Ferrante, Feresin, \& Delbello, 2001). Although there is some evidence in favor of this view in adults (e.g., McDaniel \& Einstein, 2000), there are as yet no relevant developmental data. Further, it has been suggested that whether the retrieval is automatic may depend on characteristics of the prospective and ongoing tasks, as well as individual differences (McDaniel \& Einstein, 2000). For example, whereas working memory is presumably only minimally involved over very long delays, it may play a more substantial role over shorter delays such as those instantiated in our study.

Consistent with that hypothesis, we found that working memory, as measured by the backward digit span task, was correlated with prospective memory over and above age. This suggests that not only storage of information, but also updating may be particularly important for PM. In contrast, inhibitory control, as assessed by the day/night task, was only weakly related to PM. However, children generally performed quite well on the day/night task and so ceiling effects may have constrained our ability to detect a relation. Future research might include additional inhibitory tasks to explore this relation more fully.

An analysis of covariance further showed that working memory but not inhibitory control or RM covaried with PM. Importantly, however, the interaction between age and delay remained significant even when working memory was controlled, indicating that working memory alone cannot explain our findings, and that other factors such as monitoring ability may be implicated.

Our results thus offer mixed support for EF models such as the PAM model. On the one hand, we did not find an effect of increasing the number of intentions as would be predicted in these types of models. On the other hand, the finding that working memory is correlated with PM suggests that PM relies in part on controlled processes. In addition, to the extent that introspection or monitoring affect PM, this would suggest that PM relies on controlled processes. Metacognitive processes such as these are inherently executive in nature. 
It is likely, however, that automatic processes are also important for PM (for example, prospective intentions sometimes seem to pop into mind with little or no effort). The multiprocess model (Einstein et al., 2005) proposes that PM is mediated by both automatic and controlled processes and has been suggested as a better account of the developmental PM data (Kvavilashvili, Kyle, \& Messer, 2008). Moreover, to the extent that prospective memory is accomplished with no decrement on the ongoing task, then automatic processes would seem to be involved.

One limitation of our study was that 6-year-olds were performing near ceiling on the PM task, ruling out the possibility of seeing an effect of delay or number of intentions in this age group. This finding was somewhat surprising, as Kvavilashvili et al. (2001) had used a very similar paradigm in which even 7-year-olds were not performing at ceiling. A number of modifications we made to the task may account for these differences. For example, children in Kvavilashvili et al.'s study sorted 20 cards, including only a single target card, whereas we had two target cards in each stack and 11 non-targets. The higher relative frequency of target cards may have aided children's PM in that the first target card might prime the prospective action in response to subsequent target cards.

In conclusion, we found age related changes in PM and an interaction between age and delay such that 5-year-olds performed significantly better than 4-year-olds after a long delay whereas their performance was the same after a short delay. Four-year-olds showed a non-significant tendency toward being negatively affected by a longer retention interval whereas 5-year-olds were significantly positively affected. In addition, we found evidence suggesting that executive processes, specifically working memory, are implicated in PM. Future research needs to explore further the roles of controlled and automatic processes in children's PM. More generally, the nature of children's PM should be more thoroughly studied as it is an essential life skill that has a substantial impact on academic and interpersonal functioning.

\section{References}

Atance, C. M., \& Jackson, L. K. (2009). The development and coherence of future-oriented behaviors during the preschool years. Journal of Experimental Child Psychology, 102, 379-391.

Awh, E., \& Vogel, E. K. (2008). The bouncer in the brain. Nature Neuroscience, 11, 5-6.

Brandimonte, M. A., Ferrante, D., Feresin, C., \& Delbello, R. (2001). Dissociating prospective memory from vigilance processes. Psicológica, 22, 97-113.

Brandimonte, M. A. (1991). Ricordare il futuro. Giornale Italiano di Psicologia, 3, 351-374.

Brandimonte, M. A., \& Passolunghi, M. C. (1994). The effects of cue-familiarity, cue-distinctiveness, and retention interval on prospective remembering. The Quarterly Journal of Experimental Psychology, Human Experimental Psychology, 47A, 565-587.

Burgess, P. W. (2000). Strategy application disorder: the role of the frontal lobes in human multitasking. Psychological Research, $63,279-288$.

Carlson, S. M. (2005). Developmentally sensitive measures of executive function in preschool children. Developmental Neuropsychology, 28, 595-616.

Carlson, S. M., \& Moses, L. J. (2001). Individual differences in inhibitory control and children's theory of mind. Child Development, 72, 1032-1053.

Ceci, S. J., \& Bronfenbrenner, U. (1985). Don't forget to take the cupcakes out of the oven”: Prospective memory, strategic time monitoring, and context. Child Development, 56, 152-164.

Cowan, N. (1995). Attention and memory: An integrated framework. New York: Oxford University Press.

Davis, H. L., \& Pratt, C. (1996). The development of children's theory of mind: The working memory explanation. Australian Journal of Psychology, 47, 25-31.

Diamond, A. (1988). Abilities and neural mechanisms underlying A-not-B performance. Child Development, 59, 523-527.

Einstein, G. O., Holland, L. J., McDaniel, M. A., \& Guynn, M. J. (1992). Age-related deficits in prospective memory: The influence of task complexity. Psychology and Aging, 7, 471-478.

Einstein, G. O, \& McDaniel, M. A. (1990). Normal aging and prospective memory. Journal of Experimental Psychology: Learning, Memory, and Cognition, 16, 717-726.

Einstein, G. O., \& McDaniel, M. A. (1996). Retrieval processes in prospective memory: Theoretical approaches and some new empirical findings. In M. Brandimonte, G. O. Einstein, \& M. A. McDaniel (Eds.), Prospective memory: Theory and applications (pp. 115-141). Mahwah, NJ: Erlbaum.

Einstein, G. O., McDaniel, M. A., Thomas, R., Mayfield, S., Shank, H., Morrisette, N., \& Breneiser, J. (2005). Multiple processes in prospective memory retrieval: Factors determining monitoring versus spontaneous retrieval. Journal of Experimental Psychology: General, 134, 327-342.

Ellis, J. A., \& Kvavilashvili, L. (2000). Prospective memory in 2000: Past, present and future directions. Applied Cognitive Psychology. Special Issue: New Perspectives in Prospective Memory, 14, S1-S10.

Farrar, M. J., \& Goodman, G. S. (1992). Developmental changes in event memory. Child Development, 63, 173-187.

Flavell, J. H., Green, F. L., \& Flavell, E. R. (2000). Development of children's awareness of their own thoughts. Journal of Cognition and Development, 1, 97-112. 
Gerstadt, C. L., Hong, Y. J., \& Diamond, A. (1994). The relationship between cognition and action: Performance in children 3.5-7 years old on a Stroop-like day-night test. Cognition, 53, 129-153.

Guajardo, N. R., \& Best, D. L. (2000). Do preschoolers remember what to do? Incentive and external cues in prospective memory. Cognitive Development, 1, 75-97.

Guynn, M. J., McDaniel, M. A., \& Einstein, G. O. (2001). Remembering to perform actions: A different type of memory? In H. D. Zimmer, R. L. Cohen, M. J. Guynn, J. Engelkamp, R. Kormi-Nouri, \& M. A. Foley (Eds.), Memory for action: A distinct form of episodic memory? (pp. 25-48). New York: Oxford.

Hicks, J. L., Marsh, R. L., \& Cook, G. I. (2005). Task interference in time-based, event-based, and dual intention prospective memory conditions. Journal of Memory and Language, 53, 430-444.

Hicks, J. L, Marsh, R. L., \& Russell, E. J. (2000). The properties of retention intervals and their effect on retaining prospective memories. Journal of Experimental Psychology: Learning, Memory, and Cognition, 26, 1160-1169.

Joyner, M. H., \& Kurtz-Costes, B. (1997). Metamemory development. In N. Cowan (Ed.), The development of memory in childhood (pp. 275-300). New York: Psychology Press.

Kerns, K. (2000). The CyberCruiser: An investigation of development of prospective memory in children. Journal of the International Neuropsychological Society, 6, 62-70.

Kliegel, M., \& Jäger, T. (2007). The effects of age and cue-action reminders on event-based prospective memory performance in preschoolers. Cognitive Development, 22, 33-46.

Kliegel, M., Mackinlay, R. J., \& Jäger, T. (2008). Complex prospective memory: Development across the lifespan and the role of task interruption. Developmental Psychology, 44, 612-617.

Kliegel, M., McDaniel, M. A., \& Einstein, G. O. (2000). Plan formation, retention, and execution in prospective memory: A new approach and age-related effects. Memory and Cognition, 28, 1041-1049.

Kvavilashvili, L., Kyle, F. E., \& Messer, D. J. (2008). The development of prospective memory in children. In M. Kliegel, M. A. McDaniel, \& O. Gilles (Eds.), Prospective memory: Cognitive, neuroscience, developmental, and applied perspectives (pp. 115-140). United States: Taylor \& Francis Group.

Kvavilashvili, L., Messer, D. J., \& Ebdon, P. (2001). Prospective memory in children: The effects of age and task interruption. Developmental Psychology, 37, 418-430.

Mackinlay, R.J., Kliegel, M., \& Mäntylä, T. (2009). Predictors of time-based prospective memory in children.Journal of Experimental Child Psychology, 102, 251-264.

Marsh, R. L., \& Hicks, J. L. (1998). Event-based prospective memory and executive control of working memory. Journal of Experimental Psychology: Learning, Memory, and Cognition, 24, 336-349.

Martin, M., \& Kliegel, M. (2003). Die Entwicklung komplexer prospektiver Gedachtnisleistung im Kindesalter [The development of complex prospective memory performance in children]. Zeitschrift-fur-Entwicklungspsychologie-und-PadagogischePsychologie, 35, 75-82.

McCauley, S. R., \& Levin, H. S. (2004). Prospective memory in pediatric traumatic brain injury: A preliminary study. Developmental Neuropsychology, 25, 5-20.

McDaniel, M. A., \& Einstein, G. O. (2000). Strategic and automatic processes in prospective memory retrieval: A multiprocess framework. Applied Cognitive Psychology, 14, S127-S144.

McDaniel, M. A., Robinson-Riegler, B., \& Einstein, G. O. (1998). Prospective remembering: Perceptually driven or conceptually driven processes? Memory \& Cognition, 26, 121-134.

Meacham, J. A., \& Colombo, J. A. (1980). External retrieval cues facilitate prospective remembering in children. Journal of Educational Research, 73, 299-301.

Nigro, G., Senese, V. P., Natullo, O., \& Sergi, I. (2002). Preliminary remarks on type of task and delay in children's prospective memory. Perceptual and Motor Skills, 95, 515-519.

Peterson, C. (2002). Children's long-term memory for autobiographical events. Developmental Review, 22, 370-402.

Powell, M. B., \& Thomson, D. M. (1996). Children's memory of an occurrence of a repeated event: Effects of age, repetition, and retention interval across three question types. Child Development, 67, 1988-2004.

Rendell, Vella, Kliegel, \& Terrett. (2009). Effect of delay on children's delay-execute prospective memory performance. Cognitive Development, 24, 156-168.

Smith, R. E. (2003). The cost of remembering to remember in event-based prospective memory: Investigating the capacity demands of delayed intention performance. Journal of Experimental Psychology: Learning, Memory, and Cognition, 29, 347-361.

Smith, R. E., \& Bayen, U. J. (2004). A multinomial model of event-based prospective memory. Journal of Experimental Psychology: Learning, Memory, and Cognition, 30, 756-777.

Somerville, S. C., Wellman, H. M., \& Cultice, J. C. (1983). Young children's deliberate reminding. The Journal of Genetic Psychology, 143, 87-96.

Vogel, E. K., McCollough, A. W., \& Machizawa, M. G. (2005). Neural measures reveal individual differences in controlling access to working memory. Nature, $438,500-503$

Wang, L., Kliegel, M., Liu, W., \& Yang, Z. (2008). Prospective memory performance in preschoolers: Inhibitory control matters. European Journal of Developmental Psychology, 5, 289-302.

Ward, H., Shum, D., McKinlay, L., Baker-Tweney, S., \& Wallace, G. (2005). Development of prospective memory: Tasks based on the prefrontal-lobe model. Child Neuropsychology, 11, 527-549.

Wechsler, D. (1991). Wechsler Intelligence Scale for children (third edition). San Antonio, TX: The Psychological Corporation.

Wellman, H. M., \& Liu, D. (2004). Scaling of theory-of-mind tasks. Child Development, 75, 523-541.

West, R. (1996). An application of prefrontal cortex function theory to cognitive ageing. Psychological Bulletin, 120, 272-292.

West, R., \& Craik, F. I. M. (1999). Age-related decline in prospective memory: The roles of cue accessibility and cue sensitivity. Psychology and Aging, 14, 264-272.

Zelazo, P. D. (2004). The development of conscious control in childhood. Trends in Cognitive Science, 8, 12-17. 
Zelazo, P. D., Carlson, S. M., \& Kesek, A. (2008). The development of executive function in childhood. In C. A. Nelson, \& M. Luciana (Eds.), Handbook of developmental cognitive neuroscience (pp. 553-574). Cambridge, MA: MIT Press.

Zelazo, P. D., \& Frye, D. (1998). Cognitive complexity and control II: The development of executive function in childhood. Current Directions in Psychological Science, 7, 121-126.

Zimmermann, T. D., \& Meier, B. (2006). The rise and decline of prospective memory performance across the life span. The Quarterly Journal of Experimental Psychology, 59, 2040-2046. 